\title{
AVALIAÇÃO E COMPARTILHAMENTO DE RECURSOS ESTRATÉGICOS EM DUAS EMPRESAS DE UMA CADEIA DE SUPRIMENTO DE ESTRUTURAS METÁLICAS
}

\author{
C. F. GOHR ', A. M. C. GONÇALVES e B. E. S. SANTOS \\ Universidade Federal da Paraíba \\ claudiagohr@ct.ufpb.br
}

Submetido 14/03/2016 - Aceito 17/04/20x

DOI: $10.15628 /$ holos.2017.4276

\section{RESUMO}

Este artigo tem como principal objetivo identificar e analisar os recursos estratégicos de duas empresas (uma empresa focal e um fornecedor de primeira camada) que atuam em uma cadeia de suprimentos de estruturas metálicas, utilizando como pano de fundo a visão baseada em recursos. Especificamente pretende-se verificar se os recursos identificados e avaliados são compartilhados e melhorados, de forma a analisar o potencial de ampliação de vantagem competitiva das duas empresas em função do relacionamento existente entre elas. Para tanto, foram realizados dois estudos de casos, utilizando como técnica principal de coleta de dados a entrevista semiestruturada e estruturada. Tratase de uma pesquisa aplicada e de caráter descritivo que adotou uma abordagem predominantemente qualitativa para a análise de dados. Os resultados demonstraram que as características do relacionamento entre as empresas estão relacionadas à dependência, poder, satisfação, confiança, comunicação e comprometimento. Os recursos identificados foram bem avaliados em relação aos critérios de valor, sustentabilidade e versatilidade pelas duas empresas. Os recursos mais importantes para o bom desempenho do relacionamento entre as duas empresas são informações e conhecimento. O intercâmbio desses recursos permitiu a melhoria dos seguintes recursos nas empresas: qualidade do produto, relacionamentos interpessoais, habilidade, experiência e treinamento.

PALAVRAS-CHAVE: visão baseada em recursos, cadeia de suprimentos, vantagem competitiva.

\section{ASSESSMENT AND RESOURCE SHARING IN TWO ORGANIZATIONS OF A SUPPLY CHAIN OF STEEL STRUCTURES}

\begin{abstract}
This study aims to identify and analyze strategic resources in two companies (a focal firm and one of its most important suppliers) from a supply chain of steel structures, using theoretical support from the resourcebased view. Specifically we intend to check if the identified resources are shared and improved in order to analyze the potential for expansion of competitive advantage of the two companies due of the relationship between them. We conducted two case studies, using as the main technique of data collection the semistructured and structured interviews. It is an applied and descriptive research which adopted a predominantly qualitative approach to data analysis. The results
\end{abstract}

showed that the characteristics of the relationship between the companies are related to dependence, power, satisfaction, trust, communication and commitment. The resources identified in the research field were well assessed in relation of its value, sustainability and versatility by both companies. The most important resources for the relationship between the two companies are information and knowledge resources. The exchange of these resources led to an improvement of the following resources: product quality, interpersonal relationships, skills, experience and training.

KEYWORDS: resource-based view, supply chain, competitive advantage. 


\section{INTROUÇÃO}

Os recursos estratégicos são considerados essenciais para a formulação da estratégia e também para a definição da vantagem competitiva das organizações, sendo este o pressuposto básico da visão baseada em recursos (VBR). Vários autores contribuíram para o desenvolvimento dessa teoria, tais como Penrose (1968), Wernerfelt (1984), Barney (2001) e Priem e Butler (2001) sendo que esta teoria possui uma abordagem focada nos recursos tangíveis e intangíveis das firmas no âmbito individual.

Entretanto, analisando a literatura da área nos últimos 20 anos, verificou-se um aumento das pesquisas que têm aplicado a VBR dentro do contexto de arranjos interorganizacionais, em especial, em cadeias de suprimentos. A VBR tem sido aplicada também juntamente com outras teorias, tais como a visão relacional, a teoria dos custos de transação e a própria extensão da VBR que Lavie (2006) chamou de visão baseada em recursos estendida (VBRE). Em especial, quando aplicadas nas pesquisas em cadeias de suprimentos, a principal finalidade é analisar a vantagem competitiva proporcionada pela relação entre as empresas na cadeia.

Por exemplo, Rungtusanatham et al. (2003) desenvolveram um framework conceitual baseado na VBR para descrever e explicar as vantagens oriundas das relações entre as empresas em uma cadeia de suprimentos, provenientes principalmente pelas melhorias no desempenho operacional. Com base na VBR e na literatura de gestão de cadeia de suprimentos, Wu et al. (2006) realizaram um estudo em que buscaram explicar como a tecnologia de informação (TI) pode criar vantagem competitiva sustentável em uma empresa. Os autores afirmam que as capacidades das empresas de cadeias de suprimentos podem ser catalizadores para transformar os recursos de tecnologia de informação em recursos relacionais e, consequentemente podem gerar maior valor para as empresas. Barratt \& Oke (2007) também utilizaram a VBR para identificar os fatores que proporcionam vantagem competitiva sustentável em empresas de possuem relacionamentos interorganizacionais em cadeias de suprimento. Chen, Preston \& Xia (2013) desenvolveram uma pesquisa cujo objetivo era analisar, por meio de um modelo proposto a partir da visão baseada em recursos e da visão relacional, os fatores que influenciavam no desempenho da cadeia de suprimentos de um hospital. Os autores demonstraram a importância da relação entre o hospital e seus fornecedores, apontando os efeitos positivos diretos e indiretos do relacionamento, como a troca de conhecimento e a integração de tecnologia de informação (IT), recursos considerados importantes pelas empresas.

Considerando o exposto, o principal objetivo desse artigo é identificar e analisar os recursos estratégicos de duas empresas (uma empresa focal e um fornecedor de primeira camada) que atuam em uma cadeia de suprimentos de estruturas metálicas, utilizando como pano de fundo a visão baseada em recursos. Especificamente pretende-se verificar se os recursos identificados e avaliados são compartilhados e melhorados, de forma a analisar o potencial de ampliação de vantagem competitiva das duas empresas em função do relacionamento existente entre elas. O Brasil tem se tornado um importante mercado para o setor de estruturas metálicas em função das características técnicas de seus produtos, da recente boa evolução da economia brasileira, em especial do setor de construção civil e de infraestrutura (Faleiros, Teixeira Junior \& Santana, 2012), sendo este um dos motivos para a seleção da cadeia.

Este artigo encontra-se estruturado em cinco seções, além desta introdução. A segunda é composta pelo referencial teórico, em que se apresentam os principais conceitos que deram suporte para o desenvolvimento do estudo empírico. Na terceira são apresentados os procedimentos metodológicos que nortearam o desenvolvimento da pesquisa de campo. Em 
seguida, na quarta seção, são apresentadas a descrição e a análise dos resultados. Por fim, na quinta e última seção, o artigo é finalizado com as conclusões e discussões adicionais sobre a pesquisa.

\section{REFERENCIAL TEÓRICO}

O motivo pelo qual algumas empresas tem um maior desempenho em relação às outras tem sido alvo de pesquisas em diversas áreas do conhecimento. Algumas teorias explicam que esse desempenho acima da média é explicado por elementos do ambiente externo, tal como aponta Porter (1980). Outras consideram que o sucesso competitivo e o consequente desempenho superior é uma consequência de variáveis do ambiente interno, tais como recursos e capacidades (Penrose, 1968; Wernerfelt, 1984; Teece, Pisano \& Shuen, 1997; Barney, 2001).

Nesse contexto, os recursos e capacidades são considerados essenciais para a formulação da estratégia e também para a definição da vantagem competitiva das organizações, sendo este o pressuposto básico da visão baseada em recursos (VBR) (Penrose, 1968; Wernerfelt, 1984; Teece, Pisano \& Shuen, 1997; Barney, 2001).

Um recurso pode ser definido como todos os ativos que a empresa controla e que podem ser usados para criar e implementar estratégias. Têm, portanto, grande importância na análise dos fatores que resultam no ganho de vantagem competitiva em uma organização de acordo com a VBR (Barney \& Hesterly, 2011).

Dessa forma, é fundamental que as organizações reconheçam e identifiquem os seus recursos. Para a identificação dos recursos, sugere-se a estruturação de um procedimento de análise, guiado por uma espécie de check-list, feito por categoria de recursos (Santos, Gohr \& Cruz, 2011). De acordo com Mills et al. (2002), há duas razões que tornam a categorização dos recursos importantes, são elas: (a) para que a descrição se torne mais compreensível para aquelas pessoas que não estiveram envolvidas no processo de identificação dos recursos; e, (b) para garantir que a identificação dos recursos tocou todos os recursos bases.

A categorização dos recursos pode ser feita de duas formas: primeiro, classificando os recursos em tangíveis e intangíveis, que são comumente definidos da seguinte forma (Mills et al., 2002; Wernerfelt, 1984): (i) recursos tangíveis: são aqueles recursos mais fáceis de se identificar, normalmente incluem recursos físicos; e, (ii) recursos intangíveis: são aqueles recursos difíceis de serem identificados e quantificados, normalmente incluem os recursos relacionados ao conhecimento organizacional.

Já Barney \& Hesterly (2007) classificam os recursos em físicos, financeiros, humanos e organizacionais (sendo que estes são em parte tangíveis ou intangíveis). Buscando relacionar as classificações dos recursos de acordo com Mills et al. (2002), Wernerfelt (1984) e Barney \& Hesterly (2007), o Quadro 1 foi desenvolvido.

\begin{tabular}{|c|c|c|}
\hline RECURSOS & Mills et al. (2002) & Barney e Hesterly (2007) \\
\hline \multirow{3}{*}{ TANGÍvEIS } & Estrutura física, localização, equipamentos. & FísICOS \\
\cline { 2 - 3 } & Investimentos, empréstimos, entre outros. & FINANCEIROS \\
\hline
\end{tabular}




\begin{tabular}{|c|c|c|}
\hline & $\begin{array}{l}\text { Sistemas e recursos processuais: Sistemas de } \\
\text { recrutamento, medição de desempenho, } \\
\text { recompensa, processamento de pedidos, entre } \\
\text { outros. }\end{array}$ & ORGANIZACIONAIS \\
\hline \multirow{4}{*}{ INTANGÍVEIS } & $\begin{array}{l}\text { Habilidades e experiências: Conhecimento tácito e } \\
\text { profissionais experientes. }\end{array}$ & \multirow{2}{*}{ HUMANOS } \\
\hline & Treinamento e aperfeiçoamento da mão de obra. & \\
\hline & $\begin{array}{l}\text { Recursos culturais: Cultura organizacional, } \\
\text { implementação de mudanças, relacionamentos } \\
\text { interpessoais, hierarquia. }\end{array}$ & \multirow{2}{*}{ ORGANIZACIONAIS } \\
\hline & $\begin{array}{l}\text { Recursos de rede: Reputação, relação com } \\
\text { fornecedores/clientes, relação com autoridade } \\
\text { legislativa e conselheiros. }\end{array}$ & \\
\hline
\end{tabular}

Quadro 1: Recursos tangíveis e intangíveis. Fonte: Baseado em Mills et al. (2002) e Barney \& Hesterly (2007).

Entretanto, não basta reconhecer os recursos, é necessário verificar se os mesmos são estratégicos, ou seja, se eles podem exercer impacto na vantagem competitiva. Para tanto, segundo Barney (1991), é necessário que um recurso possua as seguintes características: (i) valioso: além do valor que possui, deve saber neutralizar as ameaças e explorar as oportunidades; (ii) raro: deve ser raro entre os atuais concorrentes e os futuros; (iii) Inimitabilidade: deve ser imperfeitamente imitável, ou seja, a empresa deve desenvolver meios que dificultem a imitação do recurso; e, (iv) substituibilidade: não pode haver substitutos equivalentes para recursos que são valiosos, mas não raros e inimitáveis.

Para auxiliar na identificação dessas características, Barney \& Hesterly (2007) desenvolveram um modelo de avaliação dos recursos denominado VRIO a fim de verificar o seu potencial de geração de vantagem competitiva dentro da organização. O modelo VRIO questiona sobre o valor, a raridade, a inimitabilidade e a forma como o recurso é explorado pela organização. O Quadro 2 a seguir mostra de que modo é feita essa avaliação.

Não muito distante dos critérios estabelecidos por Barney (1991), para que os recursos sejam considerados importantes e, portanto, fontes de vantagem competitiva, Mills et al. (2002) consideram que eles precisam apresentar valor, sustentabilidade e versatilidade, denominando um modelo chamado de VSV. Dessa forma, para que um recurso forneça vantagem competitiva, ele deve seguir os seguintes critérios:

(i) valor: o recurso é valioso para os clientes, para tanto, ele deve minimizar ameaças e permitir o aproveitamento de oportunidades ambientais. Além disso, segundo os autores, para ter valor, o recurso deve ser escasso.

\begin{tabular}{|c|c|c|c|c|}
\hline \multicolumn{2}{|l|}{ O recurso ou capacidade é: } \\
\hline Valioso? & Raro? & Custoso de imitar? & Explorado pela organização? & Implicações competitivas \\
\hline Não & Não & Não & Não & Desvantagem competitiva \\
\hline Sim & Não & Não & Sim & Paridade competitiva \\
\hline
\end{tabular}




\begin{tabular}{|l|c|c|c|c|}
$\operatorname{Sim}$ & $\operatorname{Sim}$ & Não & $\operatorname{Sim}$ & Vantagem competitiva temporária \\
\hline $\operatorname{Sim}$ & $\operatorname{Sim}$ & $\operatorname{Sim}$ & $\operatorname{Sim}$ & Vantagem competitiva sustentável \\
\hline
\end{tabular}

Quadro 2: Modelo VRIO. Fonte: Barney \& Hesterly (2011, p.72).

(ii) Sustentabilidade: um recurso possui sustentabilidade quando, além de ser valioso, é difícil de ser copiado pelas empresas concorrentes;

(iii) Versatilidade: o ideal é que o recurso além de valioso e sustentável seja versátil. Essa característica refere-se ao recurso que pode ser utilizado em diversas áreas dentro da organização, em outros negócios ou no desenvolvimento de novos produtos.

Baseado no estudo de Mills et al. (2002), Santos, Gohr \&Cruz (2011) desenvolveram um método de avaliação dos recursos de acordo com os três critérios, e o aplicaram no setor hoteleiro. $\mathrm{O}$ objetivo do trabalho desenvolvido pelos autores foi analisar os recursos, pois, apesar da teoria sobre Visão Baseada em Recursos ser uma importante corrente da área de estratégia empresarial, a identificação e análise dos recursos ainda é uma área pouco explorada e de difícil aplicação. Os critérios de valor, sustentabilidade e versatilidade dos recursos desenvolvido pelos autores podem ser visualizados nos Quadro 3.

A pontuação dada é responsável por quantificar e determinar o grau de importância de cada recurso dentro da organização. Caso algumas das questões não sejam aplicáveis, elas devem ser retiradas e não serão consideradas na pontuação total (Santos, Gohr \& Cruz, 2011). A fórmula apresentada na Equação (1) a seguir, desenvolvida pelos autores, mostra como se chega à pontuação total. A intensidade do recurso, de acordo com Santos, Gohr \& Cruz (2011), é dada de acordo com a pontuação total obtida, variando de: (i) Muito baixo: 5 a 8 pontos; (ii) Baixo: 9 a 12 pontos; (iii) Médio: 13 a 17 pontos; (iv) Alto: 18 a 21 pontos; e, (v) Muito Alto: 22 a 25 pontos.

$\left[\frac{\text { Total de questões (5) }}{\text { total de questões válidas (n) }}\right] X$ Soma da pontuação das questões válidas

Apesar de a VBR ser uma importante teoria para analisar o impacto que um recurso pode exercer sobre a vantagem competitiva e, consequentemente sobre o desempenho econômico das organizações, ela tem seu foco no âmbito individual das empresas. Segundo Lavie (2006) os proponentes da VBR têm considerado as empresas como unidades independentes, desenvolvendo seus próprios conceitos de barreiras para proteção de recursos, de forma a limitar a imitação ou a substituição destes, mas voltados, especialmente, para um âmbito restrito de firmas individualmente consideradas.

\begin{tabular}{|l|c|c|c|c|c|}
\hline \multirow{2}{*}{ Valor do Recurso } & \multicolumn{5}{|c|}{ Pontuação } \\
\cline { 2 - 6 } & $\mathbf{1}$ & $\mathbf{2}$ & $\mathbf{3}$ & $\mathbf{4}$ & $\mathbf{5}$ \\
\hline $\begin{array}{l}\text { Qual é o seu efeito sobre a } \\
\text { lucratividade da organização? }\end{array}$ & Altamente negativo & $\begin{array}{l}\text { Impacto } \\
\text { negativo }\end{array}$ & Impacto nulo & $\begin{array}{c}\text { Impacto } \\
\text { positivo }\end{array}$ & $\begin{array}{c}\text { Altamente } \\
\text { positivo }\end{array}$ \\
\hline $\begin{array}{l}\text { Qual é a sua influência para ajudar a } \\
\text { empresa a não ter uma } \\
\text { desvantagem competitiva? }\end{array}$ & Altamente negativo & $\begin{array}{l}\text { Impacto } \\
\text { negativo }\end{array}$ & Impacto nulo & $\begin{array}{c}\text { Impacto } \\
\text { positivo }\end{array}$ & $\begin{array}{c}\text { Altamente } \\
\text { positivo }\end{array}$ \\
\hline
\end{tabular}




\begin{tabular}{|c|c|c|c|c|c|}
\hline $\begin{array}{l}\text { Qual é a sua influência para ajudar a } \\
\text { empresa a obter uma vantagem } \\
\text { competitiva? }\end{array}$ & Altamente negativo & $\begin{array}{l}\text { Impacto } \\
\text { negativo }\end{array}$ & Impacto nulo & $\begin{array}{l}\text { Impacto } \\
\text { positivo }\end{array}$ & $\begin{array}{l}\text { Altamente } \\
\text { positivo }\end{array}$ \\
\hline $\begin{array}{l}\text { Quantos concorrentes já possuem o } \\
\text { mesmo recurso? }\end{array}$ & Todos & A maioria & Metade & Alguns & Nenhum \\
\hline $\begin{array}{l}\text { Comparado com a concorrência, } \\
\text { qual o nível de qualidade desse } \\
\text { recurso? }\end{array}$ & $\begin{array}{l}\text { Muito abaixo da } \\
\text { média do setor }\end{array}$ & $\begin{array}{l}\text { Abaixo da } \\
\text { média do setor }\end{array}$ & $\begin{array}{l}\text { Na média do } \\
\text { setor }\end{array}$ & $\begin{array}{l}\text { No nível dos } \\
\text { melhores }\end{array}$ & $\begin{array}{l}\text { Liderança } \\
\text { inquestionável }\end{array}$ \\
\hline \multirow{2}{*}{ Sustentabilidade do Recurso } & \multicolumn{5}{|c|}{ Pontuação } \\
\hline & 1 & 2 & 3 & 4 & 5 \\
\hline $\begin{array}{l}\text { Com que facilidade os concorrentes } \\
\text { podem adquirir este recurso? }\end{array}$ & Muito facilmente & $\begin{array}{l}\text { Com certa } \\
\text { facilidade }\end{array}$ & $\begin{array}{l}\text { Com certa } \\
\text { dificuldade }\end{array}$ & Dificilmente & $\begin{array}{l}\text { O recurso é } \\
\text { único }\end{array}$ \\
\hline $\begin{array}{l}\text { Quanto tempo demora para se } \\
\text { obter um retorno financeiro sobre } \\
\text { este recurso? }\end{array}$ & $<1$ mês & $\begin{array}{l}1-6 \\
\text { meses }\end{array}$ & $\begin{array}{l}6-24 \\
\text { meses }\end{array}$ & $\begin{array}{l}2-5 \\
\text { anos }\end{array}$ & $>5$ anos \\
\hline $\begin{array}{l}\text { Qual seria o percentual de } \\
\text { faturamento para adquirir tal } \\
\text { recurso? }\end{array}$ & $<0,5 \%$ & $0,5-1 \%$ & $1-5 \%$ & $5-20 \%$ & $>20 \%$ \\
\hline $\begin{array}{l}\text { Qual a taxa de depreciação desse } \\
\text { recurso? }\end{array}$ & $>50 \%$ ano & $30-50 \%$ & $15-30 \%$ & $5-15 \%$ & $<5 \%$ \\
\hline $\begin{array}{l}\text { Sua vantagem pode ser substituída } \\
\text { por outro recurso? }\end{array}$ & Completamente & $\begin{array}{l}\text { Em grande } \\
\text { parte }\end{array}$ & Parcialmente & Dificilmente & $\begin{array}{l}\text { De forma } \\
\text { alguma }\end{array}$ \\
\hline \multirow{2}{*}{ Versatilidade do Recurso } & \multicolumn{5}{|c|}{ Pontuação } \\
\hline & 1 & 2 & 3 & 4 & 5 \\
\hline $\begin{array}{l}\text { O recurso pode ser transferido para } \\
\text { outros serviços e unidades da } \\
\text { empresa? }\end{array}$ & Impossível & $\begin{array}{l}\text { Com } \\
\text { dificuldade }\end{array}$ & $\begin{array}{l}\text { Com algum } \\
\text { esforço }\end{array}$ & Facilmente & $\begin{array}{c}\text { Muito } \\
\text { facilmente }\end{array}$ \\
\hline $\begin{array}{l}\text { Este recurso depende de recursos } \\
\text { e/ou processos complementares } \\
\text { para ser transferido? }\end{array}$ & Completa-mente & $\begin{array}{l}\text { Depende } \\
\text { bastante }\end{array}$ & Parcialmente & $\begin{array}{l}\text { Depende } \\
\text { pouco }\end{array}$ & Independente \\
\hline $\begin{array}{l}\text { Este recurso está vinculado a } \\
\text { alguma região geográfica? }\end{array}$ & Vínculo total & Vínculo forte & Vínculo parcial & Vínculo fraco & $\begin{array}{l}\text { Nenhum } \\
\text { vínculo }\end{array}$ \\
\hline $\begin{array}{l}\text { Quanto tempo demoraria para } \\
\text { reproduzir este recurso em outra } \\
\text { parte da organização? }\end{array}$ & $>5$ anos & $2-5$ anos & $6-24$ meses & 1 - 6 meses & $<1$ mês \\
\hline $\begin{array}{l}\text { A organização tem um } \\
\text { conhecimento explícito dos fatores } \\
\text { necessários para reproduzir este } \\
\text { recurso? }\end{array}$ & De forma alguma & Muito pouco & Parcialmente & $\begin{array}{l}\text { Em grande } \\
\text { parte }\end{array}$ & Completamente \\
\hline
\end{tabular}

Quadro 3: Critérios de avaliação dos recursos. Fonte: Santos, Gohr \& Cruz, 2011, p. 236, 237).

No entanto, apesar desta limitação, a VBR vem aplicada dentro do contexto de relacionamentos interorganizacionais, em especial, em cadeias de suprimentos. Quando aplicada nas pesquisas em cadeias de suprimentos, a principal finalidade é analisar a vantagem competitiva proporcionada pela relação entre as empresas na cadeia, conforme nos trabalhos desenvolvidos por Rungtusanatham et al. (2003), Wu et al. (2006), Barratt \& Oke (2007) e Chen, Preston \& Xia (2013). 
Uma cadeia de suprimentos consiste em uma série de operações na cadeia de valor, que ocorrem sequencialmente, em organizações interdependentes, cujo objetivo é atender o consumidor por meio de um fluxo operacional (Chen, 2011; Huemer, 2012; Hall \& Saygin, 2011). Por outro lado, para Paulraj \& Chen (2011), a gestão da cadeia de suprimentos deve ter como principal objetivo gerar valor ao cliente, orientando a sua mentalidade para o ambiente externo, fazendo com que a cadeia desenvolva-se constantemente e os recursos sejam aproveitados com esse objetivo.

Lambert \& Cooper (2000) referem-se à cadeia de suprimentos como "uma rede de múltiplos negócios e relacionamentos", em que a supply chain management (SCM - Gestão de cadeia de suprimentos) trata dos processos e a forma como o negócio e as relações com os outros membros devem ser geridos. Os autores adotam o conceito de SCM utilizado pelo grupo The Global Supply Chain Forum (GSCF), em que: “...é a integração dos principais processos de negócios a partir de usuário final, através de fornecedores originais que fornecem produtos, serviços e informações que agregam valor para os clientes e outras partes interessadas".

Hall \& Saygin (2011) acrescentam que o desempenho das empresas de uma cadeia de suprimentos influencia as outras organizações, assim como a sua vontade e capacidade para coordenar as atividades na cadeia.

Dessa forma, pode-se afirmar que as firmas participantes de uma cadeia de suprimentos têm, portanto, a oportunidade de gerar uma maior lucratividade do que caso agisse de forma isolada, pois, por meio do compartilhamento de recursos e informações há uma maior chance de a empresa possuir vantagem competitiva sustentável, visto que esta não está associada apenas aos recursos internos, mas ao acesso que a empresa tem aos recursos disponibilizados pelas outras organizações (Dyer \& Singh, 1998).

Nesse sentido, Pigatto \& Alcantara (2007) identificaram na literatura, ao longo da pesquisa desenvolvida por eles, um conjunto de variáveis existentes em diferentes relacionamentos interorganizacionais, inclusive em cadeias de suprimentos. De acordo com os autores, tais características podem ser formadas por ações e comportamentos adotados pelos colaboradores ou pelas próprias empresas em uma cadeia, que podem auxiliar na explicação de determinadas atitudes tomadas pelas empresas durante o período em que estas mantêm um relacionamento interorganizacional, seja colaborativo ou não. Tais características podem ser visualizadas no Quadro 4 que segue.

Segundo Pigatto \& Alcantara (2007), quanto maior o nível de colaboração existente entre as empresas, maiores serão as possibilidades de geração de vantagens competitivas para as empresas que fazem parte da cadeia. Na seção a seguir serão descritos os procedimentos metodológicos necessários para o desenvolvimento do estudo empírico.

\begin{tabular}{|l|l|}
\hline \multicolumn{1}{|c|}{ Variáveis } & \multicolumn{1}{c|}{ Autores } \\
\hline Adaptação & Wilson (1995); Leonidou \& Kaleka (1998); Crotts \& Turner (1999); Bennett \& \\
& Gabriel (2001); Fynes \& Voss (2002). \\
\hline \multirow{3}{*}{ Confiança } & Dwyer et al. (1987); Anderson \& Narus (1990); Mohr \& Spekman (1994); Morgan \\
& \& Hunt (1994); Wilson (1995); Kumar (1996); Wilson \& Vlosky (1997); Leonidou \& \\
& Kaleka (1998); Hogarth-Scott (1999); Crotts \& Turner (1999); Bennett \& Gabriel \\
& (2001); Gadde \& Hakansson (2001); Lindgreen (2001); Fynes \& Voss (2002). \\
\hline Comunicação & Mohr \& Spekman (1994); Morgan \& Hunt (1994); Leonidou \& Kaleka (1998); \\
& Crotts \& Turner (1999); Pressey \& Mathews (2000); Bennett \& Gabriel (2001). \\
\hline Comprometimento & Mohr \& Spekman (1994); Morgan \& Hunt (1994); Wilson (1995); Hogarth-Scott \\
& (1999); Leonidou \& Kaleka (1998); Wilson \& Vlosky (1998); Crotts \& Turner (1999). \\
\hline
\end{tabular}




\begin{tabular}{|l|l|}
\hline Conflito & $\begin{array}{l}\text { Morgan \& Hunt (1994); Leonidou \& Kaleka (1998); Lindgreen (2001); Gadde \& } \\
\text { Hakansson (2001). }\end{array}$ \\
\hline Cooperação & $\begin{array}{l}\text { Mohr \& Spekman (1994); Morgan \& Hunt (1994); Wilson (1995); Spekman et al. } \\
\text { (1997); Leonidou \& Kaleka (1998); Crotts \& Turner (1999); Gadde \& Hakansson } \\
\text { (2001); Lindgreen (2001); Fynes \& Voss (2002); Batt (2003). }\end{array}$ \\
\hline Cultura Organizacional & Denison (1996); Cameron \& Quinn (1999); O'Toole (2002); Hatch (2004). \\
\hline Dependência & $\begin{array}{l}\text { Mohr \& Spekman (1994); Wilson (1995); Wilson \& Vlosky (1997); Leonidou \& } \\
\text { Kaleka (1998); Crotts \& Turner (1999); Hogarth-Scott (1999); Gadde \& Hakansson } \\
\text { (2001); Lindgreen (2001); Fynes \& Voss (2002); Batt (2003). }\end{array}$ \\
\hline Investimento Específico & $\begin{array}{l}\text { Wilson (1995); Spekman et al. (1997); Crotts \& Turner (1999); Bennett \& Gabriel } \\
\text { (2001); Batt (2003). }\end{array}$ \\
\hline Poder & $\begin{array}{l}\text { Mohr \& Spekman (1994); Wilson \& Vlosky (1997); Hogarth-Scott (1999); Crotts \& } \\
\text { Turner (1999); Pressey \& Mathews (2000); Gadde \& Hakansson (2001); Lindgreen } \\
\text { (2001); Batt (2003). }\end{array}$ \\
\hline Satisfação & $\begin{array}{l}\text { Wilson (1995); Leonidou \& Kaleka (1998); Crotts \& Turner (1999); Bennett \& } \\
\text { Gabriel (2001); Fynes \& Voss (2002); Batt (2003). }\end{array}$ \\
\hline
\end{tabular}

Quadro 4: Variáveis características em relacionamentos interorganizacionais. Fonte: Pigatto \& Alcantara (2007, p. 158).

\section{PROCEDIMENTOS METODOLÓGICOS}

Este trabalho tem como principal objetivo identificar e analisar os recursos estratégicos de duas empresas (uma empresa focal e um fornecedor de primeira camada) que atuam em uma cadeia de suprimentos de estruturas metálicas, utilizando como pano de fundo a visão baseada em recursos. Especificamente pretende-se verificar se os recursos identificados e analisados são compartilhados e melhorados, de forma a analisar o potencial de ampliação de vantagem competitiva das duas empresas em função do relacionamento existente entre elas. Dessa forma, esta pesquisa adotou o método de multicasos, que, de acordo com Yin (2001) refere-se ao estudo de mais de um experimento (caso único), sendo que eles devem seguir uma lógica de replicação.

Ainda segundo Yin (2001), os resultados obtidos por meio do estudo de casos múltiplos são mais convincentes, sendo, portanto, considerado mais robusto que o estudo de caso único. No entanto, o estudo de casos múltiplos normalmente exige maior tempo e recursos por parte do pesquisador.

A pesquisa foi desenvolvida em duas empresas de uma cadeia de suprimentos de estruturas metálicas, sendo uma empresa focal e um fornecedor de primeira camada. A seleção das empresas se deu pela importância econômica da cadeia para o país e região, assim como pelo critério de acessibilidade às empresas.

Como instrumentos de coleta de dados, foram utilizadas a entrevista estruturada, semiestruturada, observação passiva (durante a pesquisa com a empresa focal) e informações disponibilizadas nos sites das duas empresas. As entrevistas nas empresas foram realizadas no período de abril a julho do ano de 2014 e foram desenvolvidas em média em 3 horas. Na empresa focal as entrevistas foram realizadas com o gerente de projetos e o gerente administrativo (denominados nesta pesquisa de Entrevistados 1 e 2), já na empresa fornecedora a entrevista foi realizada com um vendedor pleno (denominado nesta pesquisa de Entrevistado 3. Todas as entrevistas foram gravadas e transcritas.

Na Figura 1 podem ser visualizadas, de forma resumida, as etapas que foram necessárias para o desenvolvimento da pesquisa. 


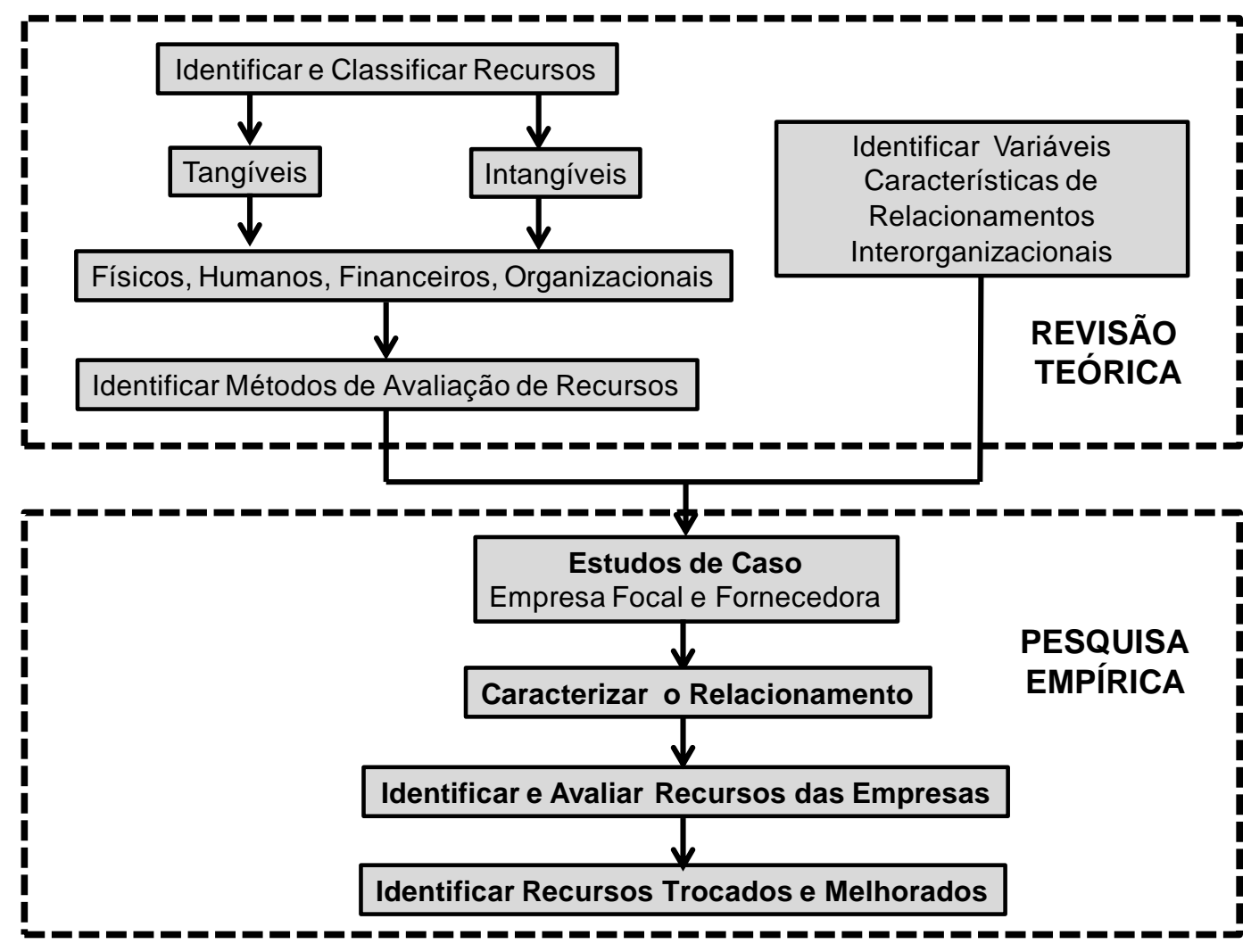

Figura 3: Etapas da pesquisa. Fonte: Elaborado pelos autores.

Primeiramente foi necessário desenvolver a revisão de literatura em periódicos nacionais da base de dados Scielo, e em periódicos internacionais, por meio base de dados do Web of Science. Por meio dos artigos encontrados foi possível identificar modelos de identificação e avaliação de recursos, assim como pesquisas relacionadas à identificação de variáveis características de relacionamentos interorganizacionais, especialmente em cadeias de suprimentos. Assim, esta primeira etapa permitiu o desenvolvimento da pesquisa empírica. Os modelos e autores utilizados para o desenvolvimento dos roteiros de entrevistas, e, consequentemente do estudo empírico, podem ser visualizados no Quadro 5. Na seção a seguir serão apresentados os resultados da pesquisa empírica.

\begin{tabular}{|c|c|c|}
\hline Atividade do estudo empírico & Categorias & Autores \\
\hline Caracterizar o relacionamento & $\begin{array}{l}\text { Adaptação, Confiança, Comunicação, } \\
\text { Comprometimento, Conflito, Cooperação, } \\
\text { Cultura Organizacional, Dependência, } \\
\text { Investimento Específico, Poder, Satisfação }\end{array}$ & Pigatto \& Alcantara (2007) \\
\hline Identificar os recursos & $\begin{array}{l}\text { Recursos tangíveis e intangíveis; financeiros, } \\
\text { humanos, organizacionais e físicos }\end{array}$ & $\begin{array}{l}\text { Mills et al. (2002) e Barney \& } \\
\text { Hesterly (2007). }\end{array}$ \\
\hline Avaliar os recursos & Modelo VSV & $\begin{array}{l}\text { Mills et al. (2002), Santos, } \\
\text { Gohr \& Cruz (2011) }\end{array}$ \\
\hline
\end{tabular}

Quadro 5: Atividades desenvolvidas no estudo empírico. Fonte: Elaborado pelos autores. 


\section{DESCRIÇÃO, ANÁLISE E DISCUSSÃO DOS RESULTADOS}

\subsection{Descrição das Empresas}

A empresa focal foi fundada no ano de 1994 e iniciou suas atividades no mercado de estruturas metálicas com a proposta diferenciada de oferecer soluções para seus clientes por meio de inovações tecnológicas. Hoje, onde praticamente todas as construções modernas são estruturadas em aço, esse posicionamento inicial possibilitou à empresa um pioneirismo e um crescimento exponencial que resultou em grande parceria, no início do ano de 2011, com um grupo de investidores.

Assim, a empresa focal é especializada na fabricação e montagem de estruturas metálicas de obras de setor óleo e gás, termoelétricas, edifícios de múltiplos pavimentos (comerciais ou residenciais), galpões (industriais ou comerciais), shopping centers, centros de distribuição e logística, supermercados, aeroportos, terminais rodoviários e ferroviários, pontes, viadutos e passarelas. A empresa está localizada próxima a rodovias federais, possibilitando o escoamento eficiente de sua produção para todas as regiões do país.

Já a empresa fornecedora é líder no segmento de aços longos no Continente Americano e uma das principais fornecedoras de aços longos especiais do mundo. Recentemente, passou também a atuar em dois novos mercados no Brasil, com a produção própria de aços planos e a expansão das atividades de minério de ferro, iniciativas que estão ampliando o mix de produtos oferecidos ao mercado e a competitividade de suas operações. A empresa possui uma capacidade instalada superior a 25 milhões de toneladas de aço por ano.

\subsection{Caracterização do relacionamento entre a empresa focal e sua fornecedora}

Conforme destacado anteriormente, a empresa focal fabrica e monta estruturas metálicas. Para tanto, necessita de fornecedores de perfis laminados, sua principal matéria-prima. Há, contudo, uma carência de fornecedores no país, o que faz com que a principal fornecedora detenha um alto poder de barganha em relação à empresa focal e a empresa fornecedora uma elevada dependência.

Os principais critérios utilizados pela empresa focal para a escolha do fornecedor da matéria-prima são preço e qualidade do produto, além da disponibilidade de entrega. A empresa fornecedora atende aos critérios exigidos pela empresa focal, fazendo com que não haja muita desconfiança de ambas as partes.

Entretanto, a manutenção do relacionamento, de acordo com os entrevistados, se dá através da reciprocidade no relacionamento (confiança e comprometimento) e da disponibilidade de crédito pela empresa fornecedora. Já a empresa fornecedora considera como um dos fatores para o fornecimento de seus produtos uma quantidade mínima de matéria-prima requerida pela empresa focal, para que a compra seja realizada, assim como os pagamentos feitos sem atraso. Contudo, quando a empresa focal necessita de uma quantidade de material inferior ao mínimo estabelecido eles recorrem a empresas fornecedoras de menor porte. Outra característica importante neste relacionamento está na atenção que a empresa fornecedora fornece para a empresa focal, realizando visitas frequentes, facilitando a comunicação entre elas. A empresa fornecedora, quando necessário, envolve-se nos projetos dos seus clientes, buscando soluções, e colabora com o desenvolvimento dos produtos necessários a empresa focal.

Dessa forma, o relacionamento entre as empresas é considerado satisfatório. A empresa focal tem a garantia de um bom serviço prestado, e a empresa fornecedora fideliza o seu cliente e 
colabora no sentido de ampliar a vantagem competitiva. De acordo com o exposto, as principais características identificadas no relacionamento entre as duas empresas podem ser visualizadas no Quadro 6.

\begin{tabular}{|l|l|}
\hline \multicolumn{1}{|c|}{ Focal } & \multicolumn{1}{c|}{ Fornecedora } \\
\hline - Dependência & - Poder \\
- Satisfação em relação ao relacionamento & - Satisfação em relação ao relacionamento \\
- Confiança & - Confiança \\
- Comunicação & - Comunicação \\
- Comprometimento & - Comprometimento \\
\hline
\end{tabular}

Quadro 6: Variáveis identificadas no relacionamento entre as duas empresas. Fonte: Pesquisa de campo.

\subsection{Identificação e avaliação dos recursos na empresa focal}

O Quadro 7 a seguir mostra os recursos considerados mais importantes pelos dois entrevistados, sendo denominados nesta pesquisa apenas de Entrevistados 01 e 02 . Os recursos considerados importantes para cada um deles foram, em sua maioria, diferentes, mas se complementaram, o que permitiu uma análise mais completa dos recursos mais importantes para a empresa. Após a identificação dos recursos, eles foram categorizados em tangíveis e intangíveis, conforme pode ser observado no Quadro 8.

\begin{tabular}{|c|c|}
\hline & Recursos \\
\hline Entrevistado 01 & Entrevistado 02 \\
\hline Relacionamentos Interpessoais & Habilidade e Experiência \\
Equipamentos & Equipamentos \\
Estrutura física & Estrutura física \\
Qualidade do produto & Sistema de gerenciamento \\
Financeiros & Financeiros \\
Localização & Treinamento \\
& Recursos de rede \\
& Recursos Culturais \\
\hline
\end{tabular}

Quadro 7: Identificação dos recursos mais importantes da empresa focal. Fonte: Pesquisa de campo.

Conforme é possível observar, há um equilíbrio entre os recursos tangíveis e intangíveis, o que mostra a importância de ambos os recursos para a organização, mesmo os recursos intangíveis sendo mais difíceis de serem identificados, por não serem palpáveis, mas mostra que a empresa preocupa-se com os valores, o conhecimento, como instrumentos de obtenção de vantagem competitiva.

\begin{tabular}{|l|l|l|l|l|l|}
\hline \multirow{2}{*}{ Recursos } & \multicolumn{2}{c|}{ Tangível } & \multicolumn{2}{c|}{ Intangível } \\
\cline { 2 - 6 } & Físico & Financeiro & Organizacional & Humano & Organizacional \\
\hline Habilidade e experiência & & & & & \\
\hline Equipamentos & & & & & \\
\hline Estrutura física & & & & & \\
\hline Sistema de gerenciamento & & & & & \\
\hline Recursos de rede & & & & & \\
\hline Treinamento & & & & & \\
\hline
\end{tabular}




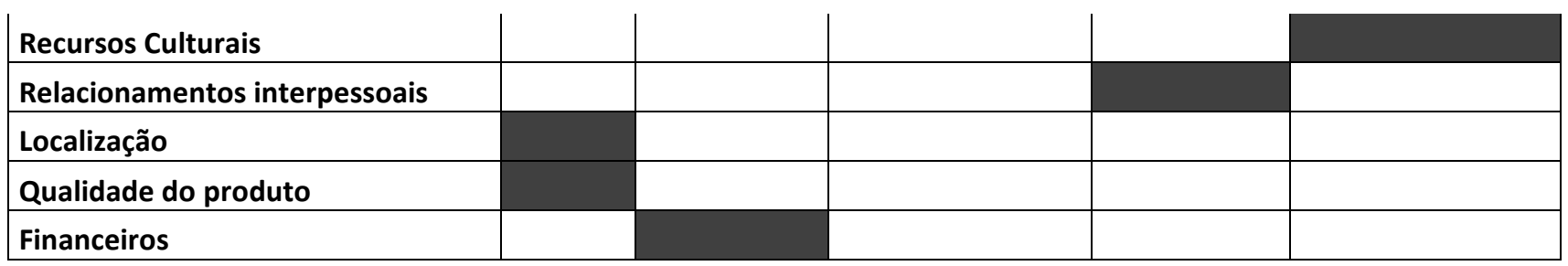

Quadro 8: Categorização dos recursos mais importantes. Fonte: Pesquisa de campo.

Após a identificação dos recursos, foi possível avaliá-los segundo os critérios VSV. Os resultados da avaliação podem ser observados no Quadro 9. Analisando o Quadro 9, pode-se observar que há recursos que ambos os profissionais destacaram, como o recurso financeiro, por meio do investimento de sócios majoritários, pois a realização de parcerias desses investidores com a organização, desde 2011, permitiu que houvesse um aumento da capacidade de produção da empresa, que se encontra em fase de crescimento, com a construção de novos prédios, consequentemente, o melhoramento da sua estrutura física (um recurso também destacado por eles).

\begin{tabular}{|l|c|c|c|c|c|c|}
\hline \multirow{2}{*}{ Recursos } & \multicolumn{2}{c|}{ Valor } & \multicolumn{2}{c|}{ Sustentabilidade } & \multicolumn{2}{c|}{ Versatilidade } \\
\cline { 2 - 7 } & $\begin{array}{c}\text { Entrevistado } \\
01\end{array}$ & $\begin{array}{c}\text { Entrevistado } \\
02\end{array}$ & $\begin{array}{c}\text { Entrevistado } \\
01\end{array}$ & $\begin{array}{c}\text { Entrevistado } \\
02\end{array}$ & $\begin{array}{c}\text { Entrevistado } \\
01\end{array}$ & $\begin{array}{c}\text { Entrevistado } \\
02\end{array}$ \\
\hline Habilidade e experiência & - & Alto & - & Alto & - & Médio \\
\hline Equipamentos & Muito Alto & Médio & Alto & Muito Alto & Médio & Baixo \\
\hline Estrutura física & Muito Alto & Alto & Alto & Muito Alto & Médio & Baixo \\
\hline Sistema de gerenciamento & - & Alto & - & Alto & - & Alto \\
\hline Recursos de rede & - & Alto & - & Médio & - & Alto \\
\hline Treinamento & - & Alto & - & Médio & - & Médio \\
\hline Recursos Culturais & - & Médio & - & Alto & - & Baixo \\
\hline Relacionamentos \\
interpessoais
\end{tabular}

Quadro 9: Avaliação dos recursos da empresa focal segundo o critério VSV. Fonte: Elaborado pelos autores.

Tal aspecto pode ser explicado pelo alto valor desse recurso, apontado pelos dois entrevistados. Isso implica, conforme as afirmações dos entrevistados, em elevado impacto nas receitas e na redução de custos, de forma a aproveitar melhor as oportunidades macroambientais e setoriais. A versatilidade desse recurso foi apontada pelos entrevistados como alta e muito alta, respectivamente, uma vez que é um recurso que pode ser aplicado em diversas áreas da organização.

Outro recurso em comum citado pelos gestores foram os equipamentos, sendo que alguns equipamentos na empresa operam com capacidade ociosa. Analisando o Quadro 09, é possível observar que esse recurso foi considerado pelo Entrevistado 01 com impacto muito alto sobre o valor, alto na sustentabilidade e médio em relação à versatilidade. Isso se deve ao fato de que na opinião dele "os equipamentos estão no nível dos melhores do mercado". Já na opinião do Entrevistado 02, ele considera que eles estão na média do setor, além de considerar que a maioria 
já possui o mesmo recurso, o que diminui o impacto deste recurso na obtenção de vantagem competitiva da organização. Além disso, de acordo com o Entrevistado 02 "esse recurso gera um custo inicial elevado, que pode ser desnecessário, visto que há equipamentos mais baratos que poderiam suprir a necessidade da empresa". De acordo com os entrevistados, a aquisição de máquinas desse porte, contudo, se dão pelo interesse do proprietário da empresa em aumentar o número de clientes em potencial.

A estrutura física também foi um recurso considerado importante por ambos entrevistados na empresa focal. De uma forma geral, esse recurso foi avaliado com valor e sustentabilidade altos e muito alto. Entretanto, quando foi avaliada a versatilidade da estrutura física, ela foi considerada como média e baixa, dada as próprias características desse recurso. É interessante destacar que os recursos financeiros, equipamentos e estrutura física são recursos tangíveis e foram considerados pelos dois entrevistados da empresa focal como importantes para o sucesso competitivo.

Um importante recurso destacado pelo Entrevistado 02 foi o recurso cultural, o qual se mostra um grande empecilho ao crescimento da organização, apesar de ser um recurso intangível. Para este Entrevistado, o valor é considerado médio, a sustentabilidade é alta (uma vez que envolve a trajetória e a história da empresa ao longo do tempo) e a versatilidade é baixa. A empresa, inicialmente, era familiar, então anteriormente as questões eram resolvidas por meio da relação direta entre funcionários e proprietário. Tal cultura ficou enraizada, o que dificulta no exercício da função dos profissionais contratados, como engenheiros e administradores, visto que, mesmo quando o profissional se reporta ao funcionário requerendo alguma mudança, este faz questão, por exemplo, de se dirigir ao proprietário questionando-o acerca das ordens dadas.

O recurso sistemas de gerenciamento, citado pelo entrevistado 02, obteve uma classificação alta em relação aos critérios valor, sustentabilidade e versatilidade, no entanto, esse recurso ainda está em fase de introdução e aperfeiçoamento, pois o mesmo ainda não trouxe os resultados esperados para a empresa. Entretanto, apesar de ser um recurso novo, ele apresenta uma série de benefícios à organização, mesmo que ainda não esteja completamente implantado.

Os demais recursos citados pelos entrevistados são em sua maioria intangíveis, com exceção dos recursos localização e qualidade do produto, citados pelo Entrevistado 1. Os outros recursos (habilidade e experiência, recursos de rede, treinamento e relacionamentos interpessoais), por serem intangíveis, são, em sua maioria, mais difíceis de serem copiados ou imitados pelas empresas concorrentes, de forma que podem conferir uma vantagem competitiva sustentável para a organização. Entretanto, apesar disso, alguns deles não foram bem avaliados pelos entrevistados, como, por exemplo, a habilidade e a experiência, que foi considerada pelo Entrevistado 2 com uma baixa versatilidade, pois, de acordo com o Entrevistado, este recurso é dificilmente transferido a outros setores da organização, visto que, apesar de possuírem o conhecimento necessário para transferi-lo, demoraria de 6 a 24 meses, e depende completamente de recursos e/ou processos complementares. Algo semelhante ocorreu com o recurso relacionamentos interpessoais, que apesar de ser considerado com um médio valor e muito alta sustentabilidade, foi considerado pelo Entrevistado $1 \mathrm{com}$ uma baixa versatilidade, pois está relacionado diretamente aos diferentes setores da organização, e, por ser um recurso intangível, exige algum esforço para que outro setor o possua, o que depende do comportamento humano, não há, portanto, um conhecimento explícito acerca deste recurso para que ele seja reproduzido em outras partes da organização. 


\subsection{Identificação e avaliação dos recursos na empresa fornecedora}

De acordo com as informações obtidas, sete recursos foram considerados importantes pelo Entrevistado 3: Habilidade e experiência; Equipamentos; Estrutura física; Sistema de gerenciamento; Localização; Treinamento; e Financeiro, conforme é possível ser observado no Quadro 10. Em seguida, eles foram avaliados segundo o modelo VSV conforme é possível observar no Quadro 11.

\begin{tabular}{|l|l|l|l|l|l|}
\hline \multirow{2}{*}{ Recursos } & \multicolumn{2}{|c|}{ Tangível } & \multicolumn{2}{c|}{ Intangível } \\
\cline { 2 - 6 } & Físico & Financeiro & Organizacional & Humano & Organizacional \\
\hline Habilidade e experiência & & & & & \\
\hline Equipamentos & & & & & \\
\hline Estrutura física & & & & & \\
\hline Localização & & & & & \\
\hline Sistema de gerenciamento & & & & & \\
\hline Recursos Financeiros & & & & & \\
\hline
\end{tabular}

Quadro 10: Categorização dos recursos mais importantes para a empresa fornecedora. Fonte: Pesquisa de campo.

\begin{tabular}{|l|c|c|c|}
\hline \multicolumn{1}{|c|}{ Recursos } & Valor & Sustentabilidade & Versatilidade \\
\hline Habilidade e experiência & Muito Alto & Médio & Médio \\
\hline Equipamentos & Muito Alto & Alto & Baixo \\
\hline Estrutura física & Muito Alto & Alto & Baixo \\
\hline Sistema de gerenciamento & Alto & Médio & Alto \\
\hline Localização & Muito Alto & Alto & Baixo \\
\hline Treinamento & Alto & Baixo & Alto \\
\hline Financeiros & Muito Alto & Médio & Alto \\
\hline
\end{tabular}

Quadro 11: Avaliação dos recursos segundo os critérios VSV (empresa fornecedora). Fonte: Elaborado pelos autores.

Os resultados apontaram uma alta intensidade para todos os recursos quanto ao item "valor", que é justificável pelo fato de a empresa ser líder de mercado no Brasil em alguns segmentos, e uma das maiores no mercado mundial, além de deter de uma grande capacidade de produção. Possui, por exemplo, recursos financeiros indiscutíveis, com mais de 120 mil acionistas, e ações listadas nas bolsas de valores de São Paulo, Nova lorque e Madri, e equipamentos com os melhores níveis de qualidade.

Considerando que o mercado de atuação da mesma requer certa tecnologia e grandes investimentos para inserção de novas empresas, essas características tornam os recursos mais valiosos, a localização das indústrias é pensada estrategicamente na logística, e é um recurso que a empresa julga bastante importante. Já a habilidade e a experiência dos profissionais são recursos com alto desempenho em relação ao valor, sendo que poucos concorrentes possuem, e que segundo o Entrevistado 3, são comuns convites de outras empresas para contratar seus profissionais para prestar treinamento da mão de obra. 
Quanto à sustentabilidade dos recursos podem-se relatar os recursos equipamentos, estrutura física e localização que tiveram um nível de desempenho "Alto" em relação ao critério sustentabilidade. Isso de seve ao planejamento da gerência quanto a logística, e ao nível de qualidade e desempenho da estrutura física e dos equipamentos, que segundo o Entrevistado 3 é de liderança inquestionável, assim esses recursos são considerados de sustentabilidade alta por serem recursos difíceis de serem copiados e consequentemente explorados, custosos de imitar e que, portanto, garantem uma vantagem competitiva para empresa que dificilmente poderia ser substituída.

No entanto, esses mesmos recursos segundo a análise possuem "baixa" versatilidade, pois são muito custosos e complexos, por isso são difíceis de serem transferidos para outras unidades da empresa. Os recursos financeiros e o treinamento da mão de obra tiveram "alta" versatilidade de acordo com a avaliação, pois por se tratarem de recursos humanos e financeiros possuem facilidade para serem transferidos para outras partes ou unidades da organização

\subsection{Análise comparativa dos recursos da empresa focal e da empresa fornecedora}

Por meio da pesquisa é possível verificar que a empresa fornecedora detém um grande poder de mercado, cuja liderança é inquestionável. Tais características destacam que a empresa focal possui uma grande dependência da empresa fornecedora, dada a política que a empresa fornecedora adota quanto a fidelidade dos clientes.

Nos Quadros 12, 13 e 14 é apresentada uma análise comparativa em relação aos recursos identificados na empresa focal e na empresa fornecedora, em relação aos critérios de avaliação adotados na pesquisa: valor, sustentabilidade e versatilidade.

De acordo com o exposto no Quadro 12, pode-se verificar que a empresa fornecedora possui várias fábricas e distribuidoras, todas localizadas de acordo com uma logística favorável, o que faz com que o recurso localização tenha um desempenho muito alto quanto ao valor que apresenta, enquanto que a empresa focal, apesar de localizar-se próxima de uma rodovia, é um recurso que os demais concorrentes possuem, encontrando-se na média do setor. De modo geral, os recursos da empresa fornecedora possuem mais valor por serem mais escassos, dada a própria história da empresa e o domínio que possuem no mercado, sendo valiosos para os clientes.

\begin{tabular}{|c|c|c|c|}
\hline \multirow{2}{*}{ Recursos } & \multicolumn{3}{|c|}{ Valor } \\
\hline & Empresa Fornecedora & Empresa Focal Ent. 01 & Empresa Focal Ent. 02 \\
\hline Habilidade e Experiência & Muito Alto & - & Alto \\
\hline Equipamentos & Muito Alto & Muito Alto & Médio \\
\hline Estrutura física & Muito Alto & Muito Alto & Alto \\
\hline Sistema de gerenciamento & Alto & - & Alto \\
\hline Localização & Muito Alto & Médio & - \\
\hline Treinamento & Alto & - & Alto \\
\hline Financeiros & Muito Alto & Muito Alto & Alto \\
\hline Recursos de rede & - & - & \\
\hline Recursos culturais & - & - & \\
\hline
\end{tabular}

Quadro 12: Análise comparativa dos recursos quanto ao valor. Fonte: Elaborado pelos autores. 


\begin{tabular}{|l|c|c|c|}
\hline \multirow{2}{*}{\multicolumn{1}{|c|}{ Recursos }} & \multicolumn{2}{c|}{ Sustentabilidade } \\
\cline { 2 - 4 } & Empresa Fornecedora & Empresa Focal Ent. 01 & Empresa Focal Ent. 02 \\
\hline Habilidade e Experiência & Médio & - & Alto \\
\hline Equipamentos & Alto & Alto & Muito Alto \\
\hline Estrutura física & Alto & Alto & Muito Alto \\
\hline Sistema de gerenciamento & Médio & - & Médio \\
\hline Localização & Alto & Muito Alto & Alto \\
\hline Treinamento & Baixo & - & Médio \\
\hline Financeiros & Médio & Muito Alto & Alto \\
\hline Recursos de rede & - & - & - \\
\hline Recursos culturais & - & & \\
\hline
\end{tabular}

Quadro 13: Análise comparativa dos recursos quanto a sustentabilidade. Fonte: Elaborado pelos autores.

\begin{tabular}{|l|c|c|c|}
\hline \multirow{2}{*}{\multicolumn{1}{c|}{ Recursos }} & \multicolumn{2}{c|}{ Versatilidade } & \multirow{2}{*}{ Empresa Focal Ent. $\mathbf{0 2}$} \\
\cline { 2 - 4 } & Empresa Fornecedora & Empresa Focal Ent. $\mathbf{0 1}$ & Médio \\
\hline Habilidade e Experiência & Médio & - & Baixo \\
\hline Equipamentos & Baixo & Médio & Baixo \\
\hline Estrutura física & Baixo & Médio & Alto \\
\hline Sistema de gerenciamento & Alto & Bédio \\
\hline Localização & Baixo & Baixo & Alto \\
\hline Treinamento & Alto & Alto & Alto \\
\hline Financeiro & Alto & - & Baixo \\
\hline Recursos de rede & - & - & \\
\hline Recursos culturais & - & & \\
\hline
\end{tabular}

Quadro 14: Análise comparativa dos recursos quanto a versatilidade. Fonte: Elaborado pelos autores.

Para ser sustentável, um recurso precisa, além de ser valioso, ser difícil de ser copiado pelos concorrentes. Por meio dos resultados apresentados no Quadro 13, nota-se que há uma boa percepção do Entrevistado 3 quanto ao desempenho desses recursos para a empresa fornecedora, em que afirma que tanto os recursos financeiros, treinamento, sistema de gerenciamento, habilidades e experiência são recursos fáceis de serem copiados.

O Quadro 14 mostra os resultados do desempenho quanto à versatilidade dos recursos, baseado nas respostas dos Entrevistados 1, 2 e 3 . Comparando, por exemplo, os recursos financeiros, todos os entrevistados consideraram este recurso quanto à versatilidade de alto desempenho. Mas, percebe-se que, considerando os demais recursos, ao se comparar a estrutura da empresa focal com a fornecedora, o número de investidores existentes e a abrangência na atuação do mercado local, nacional e internacional, percebe-se que a empresa fornecedora apresenta um desempenho financeiro elevado se comparado ao da empresa focal.

Já com relação ao recurso treinamento, a diferença nas respostas (alta para a empresa fornecedora e média para a empresa focal), pode se justificar pelo fato de que a empresa 
fornecedora, no ato da venda de seus produtos, realiza treinamentos para os seus clientes, além do fato da empresa focal ser relativamente recente, com funcionários que são treinados também pelos funcionários mais antigos, mas não há, ainda, um treinamento adequado.

Nas duas empresas, tanto os recursos localização, estrutura física e equipamentos apresentam, em geral, um baixo desempenho quanto a versatilidade, visto que são recursos difíceis de serem transferidos, a exemplo dos equipamentos, que são de grande porte.

Quanto ao recurso habilidade e experiência, os entrevistados consideraram a versatilidade deste recurso média, visto que é algo que não se transfere com facilidade e requer tempo. 0 recurso sistemas de gerenciamento foi considerado um recurso com alta versatilidade, considerando a aplicabilidade dos softwares em diversos setores das organizações e a facilidade de transferi-los. Esta análise exemplifica as diferenças na versatilidade de um recurso tangível, como o sistemas de gerenciamento, e um intangível, como o recurso habilidade e experiência, sendo os intangíveis menos versáteis, visto que as variáveis que o compõem são difíceis de se identificar, o que torna difícil transferi-lo.

\subsection{Recursos trocados e melhorados em função do relacionamento}

Foi possível constatar que os recursos identificados na pesquisa de campo não são trocados entre as duas empresas, embora esses recursos sejam melhorados em função do relacionamento entre elas, principalmente devido ao compartilhamento dos recursos informações e conhecimento. Em se tratando das informações, que é um aspecto de suma importância para caracterizar um relacionamento interorganizacional em uma cadeia de suprimentos, verificou-se que há compartilhamento de aspectos técnicos relacionados ao melhoramento da qualidade do produto e também aspectos de mercado, como acompanhamento do comportamento da demanda. Os entrevistados das empresas julgam que as informações trocadas são vitais para o relacionamento, destacando que sem a troca de informações não se cria vínculo de fidelidade, longevidade, etc.

A troca e/ou compartilhamento das informações técnicas ocorre por meio do treinamento por parte do fornecedor ao cliente, e também pelo acompanhamento do processo de produção, visando melhorá-lo, por meio do envio de colaboradores para acompanhamento do mesmo. As informações técnicas fornecidas do fornecedor para o cliente servem para monitorar a qualidade de matéria-prima corrigindo possíveis desvios de processo que possam ocorrer. Outro tipo de informação trocada entre eles está relacionada ao consumo de matéria prima, no qual são importantes para o direcionamento da programação da produção, além da programação dos prazos para a entrega. Tais informações são trocadas via e-mail, telefone, correspondências ou presencialmente, no entanto não há um sistema de informação integrado entre as duas empresas.

Quanto ao desenvolvimento conhecimentos mútuos, capacidades e/ou habilidades, o intercâmbio dos mesmos entre a empresa focal e a fornecedora ocorre por meio da prestação de treinamento por parte do fornecedor ao cliente, no qual a empresa fornecedora possui um setor de engenharia que desenvolve soluções para os clientes, um engenheiro visita seus clientes e discute os projetos que serão desenvolvidos. Também há o desenvolvimento pelo acompanhamento do processo de produção, visando melhora-lo, por meio do envio de colaboradores para acompanhamento do mesmo.

A participação da empresa focal em processos do fornecedor ocorre essencialmente durante o desenvolvimento a matéria-prima específica que atenda as necessidades da empresa focal. 
A empresa fornecedora realiza visitas frequentes na empresa focal, denominada pelos Entrevistados 1 e 2 de visitas de rotina, mediante o convite da mesma ou por interesse próprio. Nessas visitas são trocadas informações quanto as necessidades do desenvolvimento de novos materiais pelos fornecedores para cumprir as especificações técnicas do processo produtivo da empresa focal, dentre outras informações. Além de fortalecer o relacionamento interpessoal entre as empresas.

Dessa forma, de acordo com o exposto, é possível afirmar que a troca e o compartilhamento de informações e conhecimento permitiu a criação, troca e/ou melhoria nos seguintes recursos das duas empresas: qualidade do produto (empresa focal), relacionamentos interpessoais, habilidade, experiência (ambas as empresas) e treinamento (empresa focal).

\section{CONCLUSÕES}

O principal objetivo do artigo foi analisar os recursos estratégicos de duas empresas (uma empresa focal e um fornecedor de primeira camada) que atuam em uma cadeia de suprimentos de estruturas metálicas, utilizando como pano de fundo a visão baseada em recursos. Para tanto, inicialmente foi necessário caracterizar o relacionamento entre elas. Por meio da pesquisa, foi possível constatar que as variáveis características do relacionamento entre as duas empresas estão relacionadas à: dependência, poder, satisfação em relação ao relacionamento, confiança, comunicação e comprometimento.

Assim, após caracterizar o relacionamento, foi possível identificar e avaliar os recursos de acordo com os critérios de valor, sustentabilidade e versatilidade. De acordo com pesquisa de campo foi possível verificar nas duas empresas que seus recursos são, em sua maioria, valiosos, versáteis e sustentáveis, conferindo para as empresas a possibilidade de desenvolverem vantagens competitivas, de acordo com os pressupostos da VBR.

Dentre os recursos que são compartilhados entre as duas empresas, destacam-se a troca e o compartilhamento de informações e conhecimento, o que permitiu a criação, a troca e/ou melhorias nos seguintes recursos das duas empresas: qualidade do produto (empresa focal), relacionamentos interpessoais, habilidade, experiência (ambas as empresas) e treinamento (empresa focal).

Convém destacar que o pressuposto básico da VBR é que os recursos estratégicos são essenciais para a formulação da estratégia e também para a definição da vantagem competitiva das organizações. Assim, considerando o ponto de vista empresarial, os resultados possibilitaram revelar às empresas onde devem manter o foco da gestão estratégica, demonstrando quais recursos podem fazê-las obter vantagens competitivas sustentáveis, além de contribuir para melhorar a relação entre a empresa focal e seu fornecedor.

Para a análise dos recursos segundo os critérios valor, sustentabilidade e versatilidade, o trabalho avaliou os recursos de duas empresas que atuam em uma cadeia de suprimentos. Dessa forma, diferentemente Santos, Gohr \& Cruz (2011), este trabalho contribuiu para o avanço da pesquisa sobre VBR, pois aplicou esta teoria para a análise dos relacionamentos interorganizacionais existentes em uma cadeia de suprimentos.

Mintzberg, Ahlstrand \& Lampel (2000) afirmam que com o crescimento dos relacionamentos cooperativos, a formação das estratégias abandona os limites exclusivos da empresa isolada e torna-se um processo em equipe que inclui os parceiros da rede. Assim, ter conhecimento dos recursos que trazem vantagens para o relacionamento contribui para a adoção de estratégias conjuntas, que podem gerar vantagens competitivas sustentáveis. Dessa forma, 
outra contribuição da pesquisa diz respeito ao reconhecimento dos recursos que são compartilhados entre as duas empresas e de que forma estes contribuem para a melhoria dos recursos individuais de cada uma das organizações.

Como recomendações para futuras pesquisas sugere-se que a análise desenvolvida neste trabalho seja ampliada para os demais elos da cadeia de suprimentos estudada, de forma a verificar se a empresa focal objeto de investigação desta pesquisa possui outras relações de parceria com fornecedores e/ ou com clientes. Além disso, sugere-se que sejam desenvolvidos trabalhos que considerem não apenas o impacto das relações diretas, mas também a influência dos laços indiretos sobre a vantagem competitiva das empresas interconectadas em uma cadeia de suprimentos.

O trabalho iniciado neste artigo também poderia ser ampliado para analisar outros tipos de arranjos empresariais, uma vez que nesses arranjos a cooperação que envolve colaboração, parceria, confiança, compartilhamento de recursos e capacidades, assim como investimentos em ativos específicos da relação, auxiliam no desenvolvimento de vantagens competitivas além das fronteiras organizacionais, ou seja, na competitividade interorganizacional.

Por fim, sugere-se que a pesquisa desenvolvida neste trabalho seja ampliada de forma a envolver outros gestores de diferentes áreas dentro das empresas estudadas. Além disso, a identificação dos recursos que surgiram em função do relacionamento entre as empresas é algo que merece uma maior investigação de forma a verificar a possibilidade de geração de rendas relacionais, segundo a visão de Dyer \& Singh (1998).

\section{REFERÊNCIAS}

Barney, J. B. (2001). Is the resource-based "view" a useful perspective for strategic management research? Yes. Academy of Management Review, 25(1), 41-56.

Barney, J. (1991). Firm resources and sustained competitive advantage. Journal of Management, $17(1), 99-120$.

Barney, J. \& Hesterly, W.S. (2007). Administração estratégica e vantagem competitiva. São Paulo: Pearson Prentice Hall.

Barratt, M., \& Oke, A. (2007). Antecedents of supply chain visibility in retail supply chains: A resource-based theory perspective. Journal of Operations Management, 25(6), 1217-1233.

Chen, D. Q.; Preston, D. S. \& XIA, W. (2013). Enhancing hospital supply chain performance: A relational view and empirical test. Journal of Operations Management, 31(6), 391-408.

Chen, H. L. (2011). An empirical examination of project contractors' supply-chain cash flow performance and owners' payment patterns. International Journal of Project Management, 29( 5), 604-614.

Cook, L. S.; Heiser, D. R. \& Sengupta, K. (2011). The moderating effect of supply chain role on the relationship between supply chain practices and performance: an empirical analysis. International Journal of Physical Distribution \& Logistics Management, 41(2), 104-134.

Dyer, J. H.; Singh, H. (1998). The relational view: cooperative strategy and sources of interorganizational competitive advantage. Academy of Management Review, 23(4), 660-679.

Faleiros, J. P. M.; Junior, J.R.T. \& Santana, B. M. (2012). O Crescimento da indústria brasileira de estruturas metálicas e o boom da construção civil: um panorama do período 2001-2010. BNDES Setorial 35: Estruturas Metálicas, 47-84.

Hall, D. C.; Saygin, C. (2012). Impact of information sharing on supply chain performance. The International Journal of Advanced Manufacturing Technology, 58(1-4), 397-409. 
Huemer, L. (2012). Unchained from the chain: supply management from a logistics service provider perspective. Journal of Business Research, 65(2), 258-264.

Lado, A. A.; Paulraj, A. \& Chen, I. J. (2011). Customer focus, supply-chain relational capabilities and performance: evidence from US manufacturing industries. International Journal of Logistics Management, 22(2), 202-221.

Lambert, D. M. \& Cooper, M. C. (2000). Issues in supply chain management. Industrial Marketing Management, 29(1), 65-83.

Lavie, D. (2006). The competitive advantage of interconnected firms: an extension of the resourcebased view. Academy of Management Review, 31(3), 638-658.

Mills, J. et al. (2002) Competing through competences. Cambridge, UK: Cambridge University Press.

Mintzberg, H.; Ahlstrand, B. \& Lampel, J. (2000). Safári de estratégia: um roteiro pela selva do planejamento estratégico. Porto Alegre: Bookman.

Penrose, E. (1968). The theory of the growth of the firm. Oxford University Press.

Pigatto, G. \& Alcantara, R. L. C. (2007). Relacionamento colaborativo no canal de distribuição: uma matriz para análise. Revista Gestão \& Produção, 14(1), 155-167.

Prahalad, C. K. \& Hamel, G. (1990). The core competence of the corporation. Boston (MA), p. 235256.

Priem, R. L. \& Butler, J. E. (2001). Is the resource-based "view" a useful perspective for strategic management research?. Academy of Management Review, 26(1), 22-40.

Rungtusanatham, M. et al. (2003). Supply-chain linkages and operational performance: a resourcebased-view perspective. International Journal of Operations \& Production Management, 23(9), 1084-1099.

Santos, L. C.; Gohr, C. F. \& Cruz, I. K. H. (2011). Avaliação de recursos estratégicos em empresas hoteleiras de um município sul-mato-grossense. REBRAE. Revista Brasileira de Estratégia, 4(3), 231-243.

Teece, D. J.; Pisano, G. \& Shuen, A. (1997). Dinamic capabilities and strategic management. Strategic Management Journal, 18(7), 509-533.

Wernerfelt, B. (1984). A resource-based view of the firm. Strategic Management Journal, 5(2), 171-180.

$\mathrm{Wu}, \mathrm{F}$. et al. (2006). The impact of information technology on supply chain capabilities and firm performance: a resource-based view. Industrial Marketing Management, 35(4), 493-504.

Yin, R. K. (2001). Estudo de caso: planejamento e métodos. 2. ed. Porto Alegre: Bookman. 